\author{
Military Technical College \\ Kobry El-Kobbah, \\ Cairo, Egypt
}

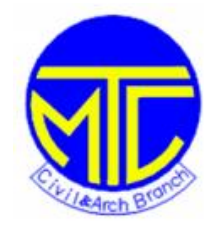

\title{
Time-Cost Tradeoff Problems Solutions for Construction Projects Using Integer Linear Programming.
}

\section{$9^{\text {th }}$ International Conference on Civil and Architecture Engineering \\ ICCAE-9-2012}

\author{
A. M. Belal *, M. K. Hasan **, I. A. Nusair *** and N. M. Badra****
}

\section{Abstract:}

Time-Cost Optimization (TCO) problem is one of the greatest challenges in construction project planning and control. TCO may be defined as a process to identify suitable construction activit ies for speeding up, and deciding "by how much" so as to attain the best possible savings in both time and cost. In this paper, an Integer Linear Model is developed to obtain solutions of time -cost tradeoff (TCT) problems in construction projects.

The proposed Model collects most related characteristics and constraints presented by different previous works. Also, new factors have been added to the model so as to represents more real TCT problems in life projects. The model is solved by Excel 2007 and verified using the commercial package Primavera (P3) throughout an application example. Good agreement results of model response against different related factors are founded through conducting sensitivity analysis.

\section{Keywords:}

Time-Cost Tradeoff, Construction project, Planning

\section{Introduction:}

Construction Management decisions are made based on developed schedules during the early planning stage of Projects. Decisions could be made by th e expertise using commercial software such as Primavera, Microsoft Project, etc. Sometimes, the output time of the scheduling process does not satisfy the desired conditions (such as the time included in the contract, etc.). Hence, to reduce the project duration, a crashing of some activities durations must be conducted. To perform the activities of a project, planners usually have to decide the construction methods or technologies, operation processes and the associated resources. However, different const ruction methods and related resource combinations for performing an activity create various durations and costs for that particular activity, and therefore, influence the total cost and duration of the project. Hence, planners have to face the decisions of finding the most cost effective way to complete a project within the desirable duration for a project. These decisions are usually made based on the so -called TCT analysis.

\begin{tabular}{r|l}
$*$ & M.T.C., Cairo, Egypt \\
$* *$ & Ph.D. Student, Civil Engineering Department, M.T.C. Ca iro, Egypt \\
$* * *$ & Ain Shams University, Cairo, Egypt \\
$* * * *$ & Ain Shams University, Cairo, Egypt
\end{tabular}


Proceedings of the $\mathbf{9}^{\text {th }}$ ICCAE-9 Conference, 29-31 May, 2012

PM 1

\subsection{Time-Cost Tradeoff studies:}

Different methods and algorithms were introduced in the literature to deal with TCT problem in construction project management. Mon, et al. [1] proposed a fuzzy PERT/cost that can be applied to a variety of fuzzy distributions of activity durations. They used $\alpha$-cut method to obtain relationships between project time and cost under different risk levels and different degrees of optimism. Tareghian and Taheri [2] proposed a meta-heuristic solution procedure for the discrete TCQT problem in order to minimize the total cost while maximizing the quality and also meeting a given deadline. Eshtehardian, et al. [3] presented a new approach for the solution of TCT problems in an uncertain environment. Fuzzy numbers were used and Fuzzy sets theory was then explicitly embedded into the optimization procedure. Błaszczyk and Nowak [4] analyzed a project scheduling problem including TCT and considering various resource allocations. Hazir, et al. [5] investigated the budget variant of the discrete TCT problem. This multi -mode project scheduling problem requires assigning modes to the activities of a project so that the total completion time is minimized and the budget and the precedence constraints are satisfied. Anagnostopoulos and Kotsikas [6] evaluated variants of a simulated annealing algorithm which solve the total cost minimization problem in activity networks in the case that discrete time-cost execution modes are allowed on the project activities. Chen and Tsai [7] proposed a novel approach for TCT analysis of a project network in fuzzy environment. The mem bership function of the fuzzy minimum total crash cost was constructed based on Zadeh's extension principle and fuzzy solutions are provided. M. Rahimi and H. Iranmanesh [8] applied a meta-heuristic algorithm for the discrete TCQT problem and multiple alternatives were considered for the activities of a project.

\subsection{Modeling of TCT problems in construction projects using Linear Programming (LP):}

The development of LP has been ranked among the most important scientific advances of the mid 20th century. Its impact has been extraordinary since 1950, and its use has been spreading rapidly . A major proportion of all scientific computation on computers is devoted to the use of LP [9]. Babu and Suresh [10] developed LP models to study the tradeoffs among time, cost, and quality. The model contains traditional activity characteristics and traditional constraints (normal duration, crashed duration, normal direct cost, crashed direct cost, and the relationships among activities are finish to start). Arikan and Gungor [11] presented a practical application of fuzzy goal LP in real life project network with two objectives as minimum completion time and crashing cost wanted to be optimized simultaneously. The membership functions $\lambda 1$ and $\lambda 2$ which expressed the total dire ct cost and total project duration $(1 \Rightarrow \lambda 1>=0 ; 1=>\lambda 2>=0)$ were summarized in one function $(\lambda)$. The optimum solution was considered to be the solution produced at $\lambda 1=$ max. No additional activity characteristics or new constraints were included in the model. Sakellaropoulos and Chassiakos [12] developed a solution method considering additional realistic project characteristics such as generalized activity precedence relations (finish to finish [FF], start to start [SS], and finish to start [FS]) and external time constraints for particular activities (an activity can not start or finish after or before a certain time or it must finish at a certain time). The possible existence of lags and leads among activities was considered in the model. Also, penalty an d bonuses costs per unit time were applied to the results obtained from the optimization process to get new results. The proposed method is formulated as a linear/integer program and provides the optimal project time -cost curve and the minimum cost schedule. The model considers indirect project costs including general expenses that cannot directly be attributed to particular activities and exist regardless of activity progress (e.g. general office expenses). Indirect costs were typically assumed to be propo rtional to project duration. Ananya and Chakraborte [13] proposed a method for the minimization of transportation cost as well as time of transportation when the demand, supply and transportation 
cost per unit of the quantities are fuzzy. The problem is mo deled as multi objective LP problem with imprecise parameters. Fuzzy parametric programming has been used to handle impreciseness and the resulting multi objective problem has been solved by goal programming approach.

\section{Problem description:}

In project planning, one of the most important issues is to achieve the scheduling of project activities. The project duration is an output of the scheduling process. Sometimes, the output duration of the scheduling process does not satisfy the desired conditions (such as the time included in the contract, etc.). Hence, to reduce the project duration, a crashing of some activities durations must be conducted. A simple representation of the possible relationship between the duration of an activity and its direct costs appears in Figure (1).

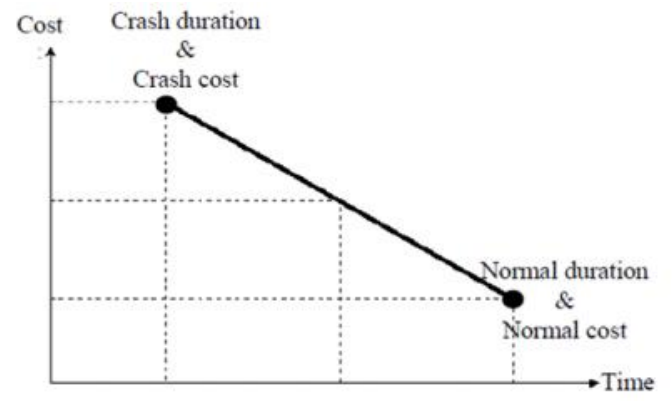

Figure (1): Illustration of linear time/cost trade-off for an activity

The linear relationship shown in Figure (1) implies that any intermediate duration could also be chosen (continuous time-cost tradeoff relationship).

The slope of the line connecting the normal point and the crash point is called the cost slope of the activity. The slope of this line can be calculated mathematically by knowing the coordinates of the normal and crash points.

Cost slope $=($ crash cost - normal cost $) /($ normal duration - crash duration $)$.

Total project costs include both direct costs and indirect costs. If each activity was scheduled for the duration that resulted in the minimum direct cost in this way, the time to complete the entire project might be too long and substantial penalties associated with the late project completion might be incurred. Thus, planners perform what is called TCT analysis to shorten the project duration. This can be done by selecting some activities on the critical paths to shorte $\mathrm{n}$ their duration.

As the direct cost for the project equals the sum of the direc $t$ costs of its activities, the project direct cost will increase by decreasing its duration. On the other hand, the indirect cost will decrease by decreasing the project duration, as the indirect cost is almost a linear function with the project duration. The decision maker has to choose the appropriate solution (consisting time and corresponding cost) from those plotted on the total cost curve as shown in Figure (2). 


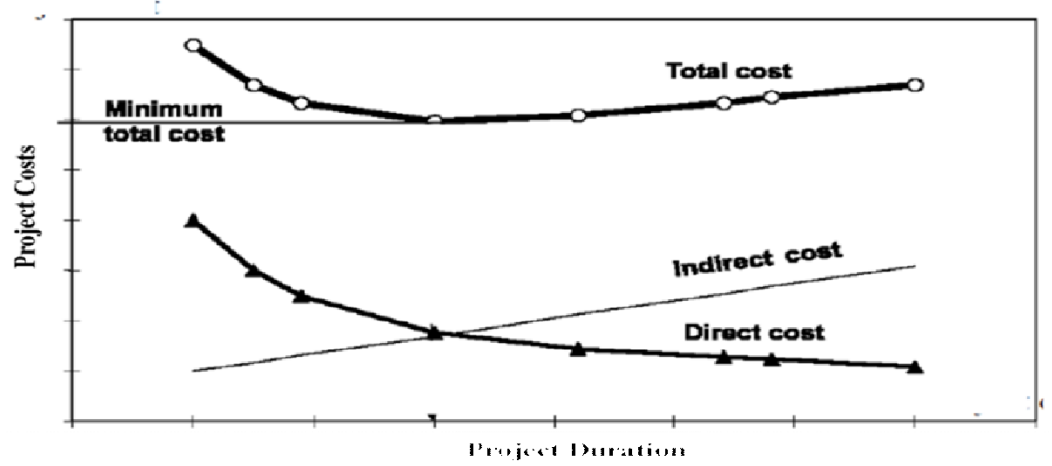

Figure (2): Illustration of direct and indirect cost relationships with the project duration.

To find solutions for the problem, planner can manually solve the problem. However, solving the problem manually can be very difficult and time-consuming, especially if the project consists of a big number of activities. So, an optimization process using a ppropriate technique is needed to find different solutions of the problem. The optimization process is constructed based on a suitable model. The model must consider most conditions and constraints related to this problem. Different conditions and constraints are presented in real projects such as ; different relationships among activities (FS, SS, and FF), external time constraints for particular activities, the possible e xistence of lags and leads among activities, penalty and bonuses costs per unit time, indirect cost, total budget, and the presence of holidays.

\section{Model (method) development:}

Assume the schedule of a project with $\mathbf{n}$ activities gives a project duration that is not satisfied by decision maker. Consequently, the project duration is needed to be crashed, so a study is conducted to get alternatives time-cost data for project activities. To get a new schedule using the original and alternative activities data, an optimization process must be conducted throughout a suitable model. The proposed model must take into account most factors related to this problem. In this paper an integer linear programming model is suggested to solve this problem. The suggeseted model consists of multiple steps as discussed below.

\section{Step 1:}

The following two basic functions presented by [11] for the project network problem are considered:

$\operatorname{Min} \mathrm{Zc}=\sum(\mathrm{Csli} * \mathrm{Tsci})$

$$
\begin{aligned}
& \forall \quad \mathrm{i} \in \mathrm{A} \\
& \forall \quad \mathrm{i} \in \mathrm{A}
\end{aligned}
$$

Where: activity $\mathrm{i}=1,2, \ldots \ldots \ldots, \mathrm{n}$

A: the set of activities, Zc: total crashed cost for the project, Z1: total completion time for the project, Csli: cost slope for activity i: Csli $=$ Ccmaxi $/$ TCmaxi where:

Ccmaxi: maximum crashed cost for activity i, TCmaxi: maximum possible crashed time for activity i, Tsci: solved crashed time for activity I (number of crashed days)

$\mathrm{tfn}$ : the finish time of the last activity (n), ts0: the start time of the first activity (0)

These two equations are subjected to the following constraints:

Start time of activity i tsi $\geq 0$

$$
\nabla \mathrm{i} \in \mathrm{A}
$$


Tsci $\geq 0$

Tsci $\leq$ TCmaxi

tsj $\geq$ tfi

$$
\forall \mathrm{i} \in \mathrm{A}
$$$$
\forall i \in A
$$

$\forall \mathrm{i}, \mathrm{j} \in \mathrm{A}$

Here: $\mathrm{j}$ is the succeeding activity of activity $i$, tsj: Start time of activity $j$

Tfi is the finish time for activity $i$, The constraint tsj $\geq t f i$ is related to the FS relationships between $i$ and $\mathrm{j}$.

Step 2:

Equation (1) expresses the total crashed cost. To get the total direct cost (Zdc), the sum of normal costs ( $\sum$ Cni) of all activities is added to the equation.

$\operatorname{Min} \mathrm{Zdc}=\sum \mathrm{Cni}+\sum(\mathrm{Csli} * \mathrm{Tsci})$

Step 3:

Most related factors and characteristics pres ented in previous works are considered in the proposed model such as; fixed and variable indirect costs, different relationships among activities (FS, SS, and FF), external time constraints for particular activities, the existence of lags and leads among activities, penalty and bonuses costs, and available budget constraint.

Step 4:

The following new factors are used in the model:

- Fixed penalty cost

- Fixed bonuses cost

- Real time factor, which is equal to the ratio between the number of days per week (7days) to the number of working days per week.

Step 5:

Based on the above steps, the new model can be constructed as following:

a) Model functions

Equation (2) calculates the project duration without considering weekly holidays (this means 7 working days per week). If the weekly holidays are presented, then the project duration will increase in a rate equal to:

$\alpha=$ number of days in a week (7days)/number of working days per week.

Therefore, multiplying equation (2) by $\alpha$ will result equation (4) that calculates the real project duration considering the presence of weekly holidays.

Min $\mathrm{Z} 1=(\mathrm{tfn}-\mathrm{ts} 0)^{*} \alpha$

Equation (3) calculates the total direct cost (total crashed cost plus total normal costs). To get the total project completion cost, the following costs must be added to equation (4):

* The indirect cost (indC) [fixed and variable indirect costs].

* The penalty cost (PC) [fixed and variable penalty costs].

* The bonuses cost (BC) [fixed and variable bonuses costs]. Adding these costs to equation (4), we get equation (5).

Min Z2 $=\sum$ Cni $+\sum($ Csli* Tsci $)+$ indC $+\mathrm{PC}-\mathrm{BC} \quad \forall i \in A$

Here $\mathrm{Z} 2$ is the total project completion cost. ind $\mathrm{C}=$ indCf $+\mathrm{indCv}$, where indCf is the fixed indirect cost and indCv is the variable indirect cost. indCv $=$ indd $* \mathrm{Z} 1$, where indd is the constant indirect cost per unit time.

$\mathrm{PC}=\mathrm{PCf}+\mathrm{PCv}$, where $\mathrm{PCf}$ is the fixed penalty cost and $\mathrm{PCv}$ is variable penalty cost. 
$\mathrm{PCv}=(\mathrm{PT}-\mathrm{Z1}) * \mathrm{Pd}$, where $\mathrm{PT}$ is the time after which penalty is considere $\mathrm{d}$ and $\mathrm{Pd}$ is the constant penalty cost per unit time.

$\mathrm{BC}=\mathrm{BCf}+\mathrm{BCv}$, where $\mathrm{BCf}$ is the fixed bonuses cost and $\mathrm{BCv}$ is the variable penalty cost.

$\mathrm{BCv}=(\mathrm{BT}-\mathrm{Z1}) * \mathrm{Bd}$, where $\mathrm{BTis}$ the time before which bonuses is considered and $\mathrm{Bd}$ is the constant bonuses cost per unit time.

The finish time of each activity $\mathrm{i}$ (tfi) is calculated as:

tfi $=$ tsi + Tni - Tsci ; where Tni, tsi, and Tsci are explained in step 1 .

b) Model constraints

The model equations (4 and 5) are subjected to the following constraints :

tsi $\geq 0$ and Tsci $\geq 0$

Tsci $\leq$ TCmaxi

For FS relationship, the start time of activity $\mathrm{j}>=$ start time of $\mathrm{i}$ plus lags (or leads) between $\mathrm{j}$ and $\mathrm{i}$ (lags have positive values, while leads have ne gative ones):

tsj $\geq$ tfi + Lij

For FF relationship, the finish time of activity $\mathrm{j} \geq$ finishes time of $\mathrm{i}$ plus lags (or leads) between $\mathrm{j}$ and $\mathrm{i}$ : tfj $\geq \mathrm{tfi}+\mathrm{Lij}$

For SS relationship, the start time of activity $\mathrm{j} \geq$ start time of $\mathrm{i}$ plus lags (or leads) between $\mathrm{j}$ and $\mathrm{i}$ : tsj $\geq$ tsi + Lij

Activity i must finish before a certain time (t): tfi $\leq \mathrm{t} / \alpha$.

Activity i must start before a certain time (t): tsi $\leq \mathrm{t} / \alpha$.

Activity i must start at a certain time $(\mathrm{t}): \mathrm{tsi}=\mathrm{t} / \alpha$.

Activity i must finish at a certain time $(\mathrm{t}): \mathrm{tfi}=\mathrm{t} / \alpha$.

Total completion cost must be equal or smaller than available budget: $\mathrm{Z} 2 \leq$ budg.

The start time and the solved crashed time of each activity i must be integer numbers (tsi = integer, Tsci $=$ integer). Penalty and bonuses costs are considered in equation (2) with respect to the following conditions:

IF Z1 > PT, THEN: PC $=$ PCf + PCv; ELSE: $\quad$ PC $=0$

IF Z1 < BT, THEN: $\mathrm{BC}=\mathrm{BCf}+\mathrm{BCv} ; \quad \mathrm{ELSE}: \quad \mathrm{BC}=0$

\section{Solution procedure:}

1) Project duration (Z1) can be expressed by the membership function $(\lambda 1)$ as presented by [11]: $0 \leq \lambda 1 \leq 1: \lambda 1=(\operatorname{maxZ1}-\mathrm{Z1}) /(\operatorname{maxZ1}-\operatorname{minZ} 1)$, Where maxZ1: normal project duration; minZ1: project duration at maximum crashing as shown in Figure 3, Z1: resulted project duration .

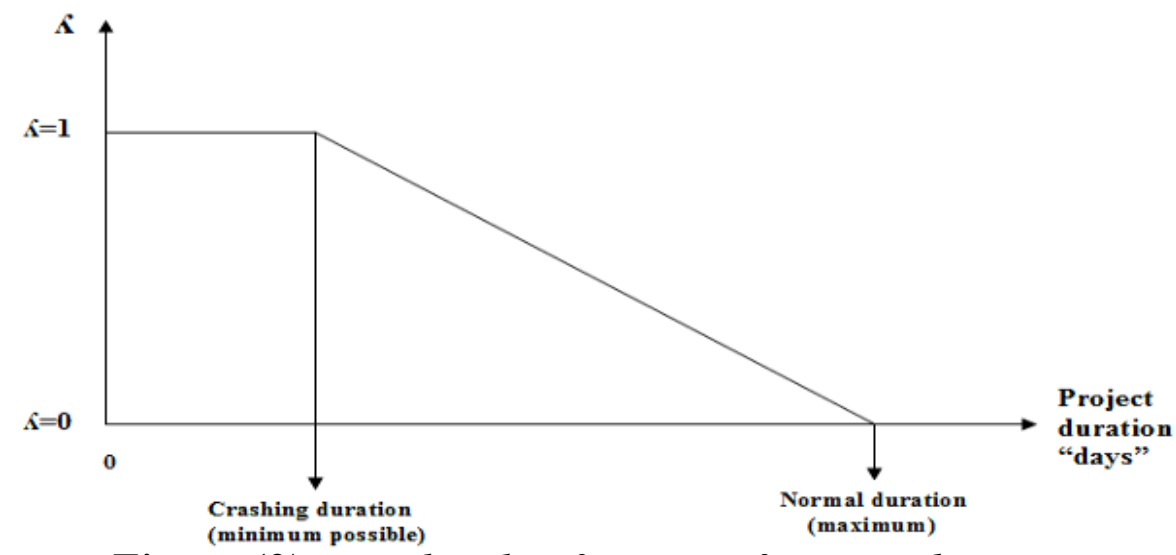

Figure (3): Membership function of project duration 
2) $\lambda 1$ is divided to 10 intervals $([0 \sim 0.1],[0.1 \sim 0.2],[0.2 \sim 0.3],[0.3 \sim 0.4],[0.4 \sim 0.5],[0.5 \sim$ 0.6], [0.6 0.7], [0.7 0.8], [0.8 0.9], [0.9 1]) in addition to $\lambda 1=0$, and $\lambda 1=1$.

3 ) For each interval of $\lambda 1$-value, the model is solved to get the minimum total cost (Z2) and corresponding project duration (Z1).

4) Z2-values resulted at each interval are plotted against the corresponding values of $Z 1$ to get the optimum TCT curve of project activities.

5) The decision-maker can choose the appropriate solution from the resulted time-cost tradeoff curve.

\section{An application example:}

The data presented by [12] from a highway construction project is used. The project refers to the upgrading of an existing two-lane undivided highway to a four-lane divided motorway with controlled traffic access. In this application, a $100 \mathrm{~m}$ road section length is considered for simplicity. The data for the project of 29 activities is shown in Table (1).

Table (1): activities data

\begin{tabular}{|c|c|c|c|c|c|c|}
\hline Activity & $\begin{array}{c}\text { Normal } \\
\text { Time } \\
\text { (Tni), } \\
\text { day }\end{array}$ & $\begin{array}{c}\text { Crash } \\
\text { Time } \\
\text { (Tci), } \\
\text { day }\end{array}$ & $\begin{array}{c}\text { Normal Cost } \\
\text { (lower pound) } \\
\text { (Cni), } \\
\text { unit }\end{array}$ & $\begin{array}{c}\text { Crash Cost } \\
\text { (upper pound) } \\
\text { (Cci), } \\
\text { unit }\end{array}$ & 芯 & $\begin{array}{c}\text { Lags } \\
(+) \\
\text { Or } \\
\text { Leads } \\
(-)\end{array}$ \\
\hline \multicolumn{7}{|l|}{ Service $\operatorname{road} A$} \\
\hline 1-Rock excavation & 5 & 4 & 2030 & 2300 & $\mathbf{0}$ & $\mathbf{0}$ \\
\hline 2- Embankment construction & 8 & 6 & 1020 & 1510 & 1(FS) & -3 \\
\hline 3- Sub base and base layers & 8 & 6 & 1700 & 2090 & $\begin{array}{l}\text { 1(FS) } \\
\text { 2(FS) }\end{array}$ & $\begin{array}{l}\mathbf{0} \\
\mathbf{0}\end{array}$ \\
\hline 4- Asphalt layer & 4 & 3 & 590 & 730 & 3(FS) & $\mathbf{0}$ \\
\hline 5- Temporary marking and signing & 2 & - & 90 & - & 4(SS) & +1 \\
\hline \multicolumn{7}{|l|}{ Service road B } \\
\hline 6-Earth and semi-rock excavation & 4 & 3 & 910 & 1100 & 1(FS) & $\mathbf{0}$ \\
\hline 7-Embankment construction & 2 & - & 250 & - & $\begin{array}{l}2 \text { 2(FS) } \\
\text { 6(FS) }\end{array}$ & $\begin{array}{c}0 \\
-1\end{array}$ \\
\hline 8-Subbase and base layers & 7 & 5 & 1490 & 1830 & $\begin{array}{l}\text { 3(FS) } \\
7(\mathbf{F S})\end{array}$ & $\begin{array}{l}\mathbf{0} \\
\mathbf{0}\end{array}$ \\
\hline 9-Asphalt layer & 4 & 3 & 520 & 750 & $\begin{array}{l}4(\mathrm{FS}) \\
8(\mathrm{FS})\end{array}$ & $\begin{array}{l}\mathbf{0} \\
\mathbf{0}\end{array}$ \\
\hline $\begin{array}{l}\text { 10-Temporary marking and } \\
\text { signing }\end{array}$ & 2 & - & 90 & - & $\begin{array}{l}\mathbf{5}(\mathrm{FS}) \\
\mathbf{9 ( F F )}\end{array}$ & $\begin{array}{c}0 \\
+1 \\
\end{array}$ \\
\hline \multicolumn{7}{|l|}{ Main road } \\
\hline 11-Traffic diversion & 1 & - & 50 & - & $\begin{array}{c}\text { 5(FS) } \\
10(\mathrm{FF})\end{array}$ & $\begin{array}{l}\mathbf{0} \\
\mathbf{0}\end{array}$ \\
\hline 12-Rock excavation & 8 & 6 & 3260 & 3710 & $11(F S)$ & $\mathbf{0}$ \\
\hline $\begin{array}{l}\text { 13-Earth and semi-rock } \\
\text { excavation-existing pavement }\end{array}$ & 5 & 3 & 1140 & 1720 & $12(\mathrm{SS})$ & +2 \\
\hline $\begin{array}{l}\text { 14- Sub grade stabilization, } \\
\text { retaining wall/culvert construction }\end{array}$ & 4 & 3 & 300 & 450 & 13(SS) & +2 \\
\hline
\end{tabular}




\begin{tabular}{|c|c|c|c|c|c|c|}
\hline 15-Embankment construction & 8 & 5 & 1020 & 1430 & $\begin{array}{l}\text { 12(FS) } \\
14(F S)\end{array}$ & $\begin{array}{l}-4 \\
-2\end{array}$ \\
\hline 16-Drainage pipe construction & 9 & 6 & 790 & 1180 & $15(\mathrm{FS})$ & -6 \\
\hline 17-Drainage layer & 13 & 11 & 3340 & 4060 & $15(\mathrm{SS})$ & +4 \\
\hline 18-Planting at roadway verges & 9 & 7 & 470 & 830 & $15(\mathrm{FS})$ & +4 \\
\hline $\begin{array}{l}\text { 19- El. installations at roadway } \\
\text { verges }\end{array}$ & 6 & 4 & 460 & 810 & $15(\mathrm{FS})$ & $\mathbf{0}$ \\
\hline 20- Ditches & 6 & 5 & 1280 & 1430 & $17(\mathrm{SS})$ & +3 \\
\hline 21- Sub base layer & 14 & 10 & 1090 & 1560 & $20($ SS $)$ & +2 \\
\hline 22- Base layer & 14 & 9 & 900 & 1400 & 21(SS) & +2 \\
\hline 23- Median island (New Jersey) & 14 & 11 & 2220 & 2690 & $22(\mathrm{FS})$ & -9 \\
\hline $\begin{array}{l}\text { 24- Elect. installation in median } \\
\text { island }\end{array}$ & 3 & - & 230 & - & 23(SS) & +6 \\
\hline 25- Asphalt layer \#1 & 6 & 4 & 1590 & 1990 & $23(\mathrm{FS})$ & -4 \\
\hline 26- Asphalt layer \#2 & 10 & 8 & 2630 & 3240 & $25(\mathrm{SS})$ & +4 \\
\hline 27- Friction course overlay & 8 & 6 & 2060 & 2660 & 26(FS) & $\mathbf{0}$ \\
\hline 28 -Final marking and signing & 10 & 8 & 320 & 610 & 27(FS) & -3 \\
\hline 29- Traffic restoration & 1 & - & 50 & - & 28(FS) & $\mathbf{0}$ \\
\hline
\end{tabular}

An external constraint is set for the completion time of the service road s. In particular, the latest finish time of activity 11 is 23 days after the beginning of the project. The variable indirect project cost is 150 units per day. Further, a variable penalty at a rate of 200 units per day of delay applies after the 80th day while a variable bonus of 100 units per day is given for project completion before the 80th day.

In this case study, fixed indirect, penalty and bonuses costs were not considered (this means that indCf $=0, \mathrm{PCf}=0$, and $\mathrm{BCf}=0$ ). The holiday days were not taking into account ( 7 working days per week), so in our model this can be expressed by giving a value equal to (1) to the real time factor $(\alpha)$. Available project budget is not presented, so this constraint will not be considered in the solution. The project network is shown in Figure (4).

To get the optimum solution for project problem, the membership function is expressed as: $\lambda 1=(\max Z 1-Z 1) /(\operatorname{maxZ} 1-\operatorname{minZ} 1)$.

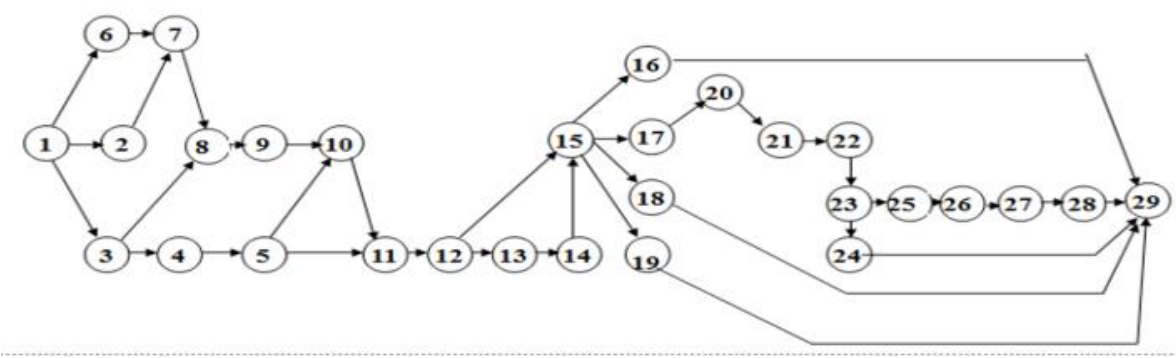

Figure (4): project network 
-Model running at minimum possible crashing (this means at mi nimum direct cost), we get project duration $=\operatorname{maxZ1}=85$ days. Model running at $\operatorname{minZ1}$, we get project duration $=\operatorname{minZ} 1=70$ days . So, membership function can be presented as:

$\lambda 1=(85-\mathrm{Z} 1) /(85-70)$.

-Model running for all $\Lambda$ 1-intervals at minZ2, we calculate Z2-values and corresponding Z1-values. The model solutions are presented in Table (2) and plotted in Figure (5).

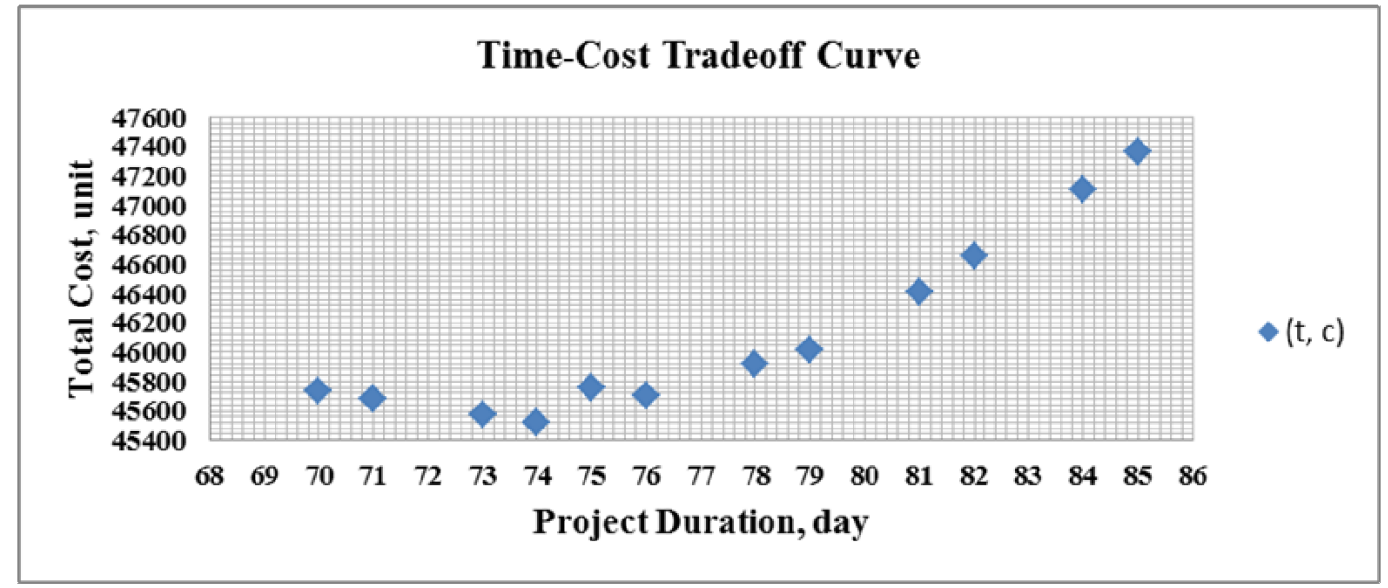

Figure (5): Optimum Time-Cost Tradeoff Curve for original case study

It can be seen that minZ2 to complete the project can be achieved by $\mathrm{Z} 1$ equal to 74 days. It is noted that, all solutions with $\mathrm{Z} 1 \geq 75$ are dominated by the solution $(\mathrm{Z} 1=74, \mathrm{Z2}=45521)$.

Table (2): Time-cost solutions

\begin{tabular}{|c|c|c|c|c|c|c|c|}
\hline $\begin{array}{c}\lambda 1 \text {-interval } \\
\text { interval }\end{array}$ & Z1, days & $\lambda 1$-value & Direct Cost & $\begin{array}{c}\text { Indirect } \\
\text { Cost }\end{array}$ & $\begin{array}{c}\text { Bonuses } \\
\text { Cost }\end{array}$ & $\begin{array}{c}\text { Penalty } \\
\text { Cost }\end{array}$ & Z2, unit \\
\hline 0 & 85 & 0 & 33610 & 12750 & 0 & 1000 & 47360 \\
\hline $0-0.1$ & 84 & 0.06667 & 33710 & 12600 & 0 & 800 & 47110 \\
\hline $0.1-0.2$ & 82 & 0.2 & 33960 & 12300 & 0 & 400 & 46660 \\
\hline $0.2-0.3$ & 81 & 0.26667 & 34055 & 12150 & 0 & 200 & 46405 \\
\hline $0.3-0.4$ & 79 & 0.4 & 34260 & 11850 & 100 & 0 & 46010 \\
\hline $0.4-0.5$ & 78 & 0.46667 & 34417 & 11700 & 200 & 0 & 45917 \\
\hline $0.5-0.6$ & 76 & 0.6 & 34707 & 11400 & 400 & 0 & 45707 \\
\hline $0.6-0.7$ & 75 & 0.66667 & 35007 & 11250 & 500 & 0 & 45757 \\
\hline $0.7-0.8$ & 74 & 0.73333 & 35021 & 11100 & 600 & 0 & 45521 \\
\hline $0.8-0.9$ & 73 & 0.8 & 35321 & 10950 & 700 & 0 & 45571 \\
\hline $0.9-1$ & 71 & 0.93333 & 35931 & 10650 & 900 & 0 & 45681 \\
\hline 1 & 70 & 1 & 36231 & 10500 & 1000 & 0 & 45731 \\
\hline
\end{tabular}

Of course, this will not be a reason to exclude these solutions. The project team might not be able to execute the activities with the applied crashing (for the first four solutions). Therefore, the presence of other solutions is very important. 
To verify the schedule of project activities, we use the new resulted activities durations (for solu tion $\mathrm{Z} 1=74$ days and $\mathrm{Z} 2=45521$ ) as an input data. This can be done manually or using commercial software such as primavera project planner (P3). The resulted schedule is shown in Figure (6).

Figure (6): Project schedule at solution $Z 1=74$ days and $Z 2=45521$ units.

\begin{tabular}{|c|c|c|c|c|c|c|c|c|c|}
\hline $\begin{array}{c}\text { Activity } \\
\text { ID }\end{array}$ & $\begin{array}{c}\text { Activity } \\
\text { Description }\end{array}$ & \begin{tabular}{|l} 
Orig \\
Dur
\end{tabular} & \begin{tabular}{|c|}
$R e m$ \\
Dur
\end{tabular} \mid & $\%$ & $\begin{array}{l}\text { Early } \\
\text { Start }\end{array}$ & $\begin{array}{l}\text { Early } \\
\text { Finish }\end{array}$ & \begin{tabular}{|l|l} 
SEP & OCT \\
$17,24,1,8$ & $15,22,2$
\end{tabular} & $\frac{2011}{1} \frac{110 \mathrm{~V}}{129,5,12,19,26}$ & $\frac{1}{\frac{D}{26,3,10,17,24}}$ \\
\hline 10 & 1 & 4 & 4 & 0 & 010Cт11 & 04OCT11 & $\nabla 1$ & & \\
\hline 20 & 2 & 6 & 6 & 0 & $020 \mathrm{CT} 11$ & 070Ст11 & $E_{\nabla}$ & & \\
\hline 30 & 3 & 6 & 6 & 0 & 080CT11 & $130 \mathrm{CT} 11$ & $\Delta 3$ & & \\
\hline 40 & 4 & 4 & 4 & 0 & $140 \mathrm{CT}^{11}$ & $170 \mathrm{CT} 11$ & $\Delta \nabla 4$ & & \\
\hline 50 & 5 & 2 & 2 & 0 & $150 \mathrm{CT} 11$ & $160 \mathrm{CT} 11$ & $\Delta \nabla \nabla 5$ & & \\
\hline 60 & 6 & 4 & 4 & 0 & 050CT11 & 080CT11 & $\Delta \nabla \nabla 6$ & & \\
\hline 70 & 7 & 2 & 2 & 0 & 080Ст11 & 090Ст11 & $\Delta \nexists \nabla 7$ & & \\
\hline 80 & 8 & 5 & 5 & 0 & $140 \mathrm{CT} 11$ & $180 \mathrm{CT} 11$ & $\Delta \nabla 8$ & & \\
\hline 90 & 9 & 3 & 3 & 0 & $190 \mathrm{CT} 11$ & 210CT11 & $\Delta 9$ & & \\
\hline 100 & 10 & 2 & 2 & 0 & $210 C T 11$ & $220 \mathrm{CT} 11$ & $\Delta 10$ & & \\
\hline 110 & 11 & 1 & 1 & 0 & $230 \mathrm{CT} 11$ & 230टा1\% & $\nabla 11$ & & \\
\hline 120 & 12 & 8 & 8 & 0 & $240 \mathrm{CT} 11$ & $310 \mathrm{CT} 11$ & $\vec{A}$ & 12 & \\
\hline 130 & 13 & 5 & 5 & 0 & $260 \mathrm{CT} 11$ & 300 CT11 & & $\nabla 13$ & \\
\hline 140 & 14 & 3 & 3 & 0 & $280 \mathrm{CT} 11$ & $300 \mathrm{CT}^{11}$ & $\Delta$ & 814 & \\
\hline 150 & 15 & 8 & 8 & 0 & 290CT11 & OSNOV11 & & -715 & \\
\hline 160 & 16 & 9 & 9 & 0 & 310СТ11 & 08NOV11 & & $\Delta \nabla 7$ & $\nabla 16$ \\
\hline 170 & 17 & 13 & 13 & 0 & $02 N O V 11$ & 14NOV 11 & & & \\
\hline 180 & 18 & 9 & 9 & 0 & 10NOV11 & 18NOV11 & & $\Delta \Rightarrow$ & $\longrightarrow 18$ \\
\hline 190 & 19 & 6 & 6 & 0 & DENOV11 & 11NOV11 & & $\Delta \nabla$ & $\longrightarrow 19$ \\
\hline 200 & 20 & 6 & 6 & 0 & 05NOV11 & 10NOV11 & & $\Delta 20$ & \\
\hline 210 & 21 & 14 & 14 & 0 & 07 NOV11 & 20 NOV11 & & $\triangle \quad \nabla 21$ & \\
\hline 220 & 22 & 9 & 9 & 0 & 09NOV11 & 17NOV11 & & $\nabla 22$ & \\
\hline 230 & 23 & 11 & 11 & 0 & 09NOV11 & 19NOV11 & & $\triangle 23$ & \\
\hline 240 & 24 & 3 & 3 & 0 & $15 N O V 11$ & 17 NOV11 & & $\Delta$ & $\longrightarrow 24$ \\
\hline 250 & 25 & 6 & 6 & 0 & 16 NOV11 & 21NOV11 & & $\sim \nabla 25$ & \\
\hline 260 & 26 & 10 & 10 & 0 & 20NOV11 & 29NOV11 & & $\triangle \triangle$ & $\nabla 26$ \\
\hline 270 & 27 & 8 & 8 & 0 & 30 NOV11 & 07DEC11 & & & $\triangle 27$ \\
\hline 280 & 28 & 8 & 8 & 0 & OSDEC11 & 12DEC11 & & & $\triangle \nabla 28$ \\
\hline 290 & 29 & 1 & 1 & 0 & 13DEC11 & 13DEC 11 & & & $\nabla 29$ \\
\hline
\end{tabular}

It can be seen that project starts at 1/10/2011 and finishes at 13/12/2011 (74 days). Also activity 11 finishes at 23/10/2011 (23 days after project start).

\section{Sensitivity analysis:}

In this section, the sensitivity of the proposed model against different factors is studied. This is done by an illustrative sensitivity analysis for the application example.

\subsection{Available budget:}

Assume a constraint budget of 46000 units is considered for the project. The resulted TCT curve is shown in Figure (7).

\section{Time-Cost Tradeoff Curve}

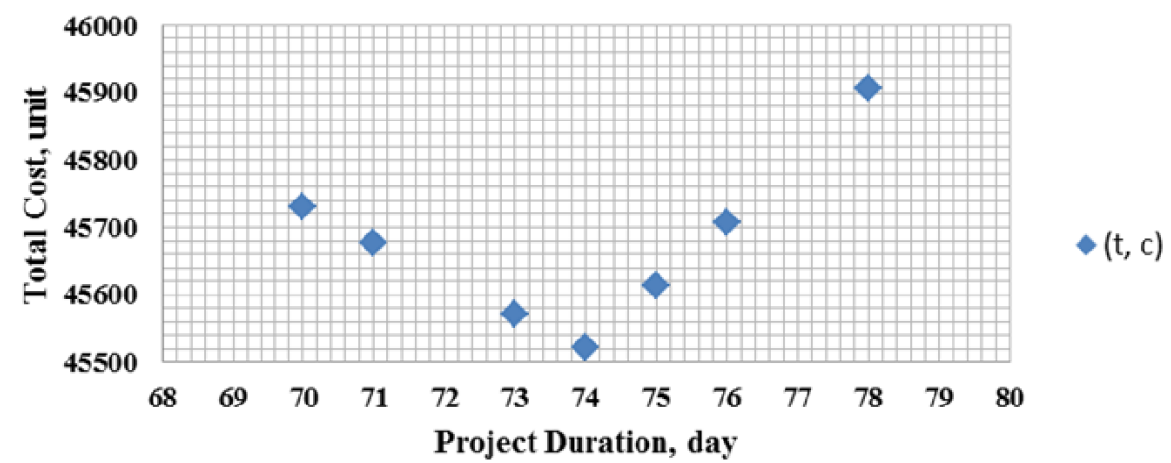

Figure (7): Optimum TCT curve at case where available budget $<=46000$ units. 
It can be shown that all solutions with Z2 $>46000$ are excluded from the original TCT curve .

\subsection{Generalized activities characteristics :}

Considering activity 15 cannot start before 35 days from the project start, then the TCT curve at this case is presented in Figure (8).

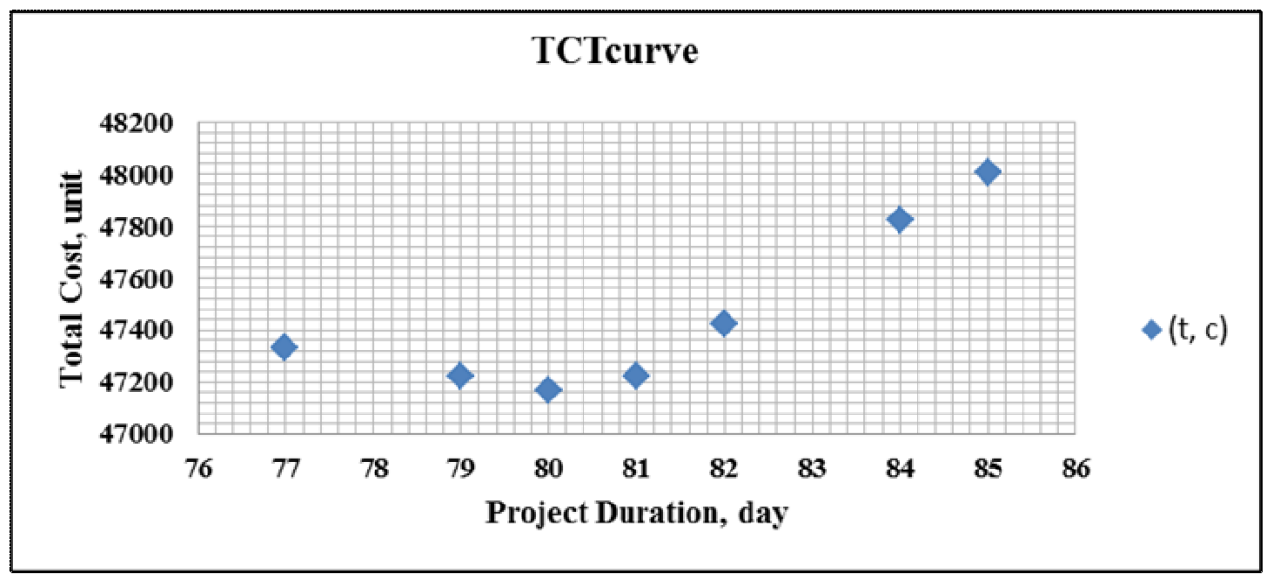

Figure (8): Optimum TCT curve at case where activity 15 cannot start before 35 days

It can be seen that Z1-values increased due to the increase of start time of activity 15 . The model solution $(\mathrm{Z} 1=80$ days, $\mathrm{Z2}=47171$ units $)$ is solved by $\mathrm{P} 3$ as shown in Figure (9).

\begin{tabular}{|c|c|c|c|c|c|c|c|c|}
\hline $\begin{array}{c}\text { Activity } \\
\text { ID }\end{array}$ & $\begin{array}{c}\text { Activity } \\
\text { Description } \\
\end{array}$ & $\begin{array}{l}\text { Orig } \\
\text { Dur } \\
\end{array}$ & \begin{tabular}{|c|} 
Rem \\
Dur
\end{tabular} & $\%$ & $\begin{array}{l}\text { Early } \\
\text { Start }\end{array}$ & $\begin{array}{l}\text { Early } \\
\text { Finish } \\
\end{array}$ & \begin{tabular}{|l|l|} 
SEP & OCT \\
$17,24,1,8,15,22,29$ \\
\end{tabular} & 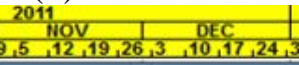 \\
\hline 10 & 1 & 4 & 4 & 0 & $010 \mathrm{CT} 11$ & 040CT11 & \multirow{5}{*}{$\begin{array}{l}\nabla 1 \\
\nabla 2 \\
\Delta \nabla_{3} \\
\Delta \nabla_{4} \\
\Delta \nabla_{5}\end{array}$} & \\
\hline 20 & 2 & 6 & 6 & 0 & 020CT11 & 070CT11 & & \\
\hline 30 & 3 & 6 & 6 & 0 & 080CT11 & $130 \mathrm{CT} 11$ & & \\
\hline 40 & 4 & 4 & 4 & 0 & 14OCT11 & 170CT11 & & \\
\hline 50 & 5 & 2 & 2 & 0 & $150 \mathrm{CT} 11$ & $160 \mathrm{CT} 11$ & & \\
\hline 60 & 6 & 4 & 4 & 0 & 050СТ11 & 080CT11 & \multirow{5}{*}{$\begin{array}{l}\Delta \nabla \nabla 6 \\
\Delta \nabla \nabla 7 \\
\Delta \nabla 8 \\
\Delta \nabla 9 \\
\Delta 1_{10}\end{array}$} & \\
\hline 70 & 7 & 2 & 2 & 0 & 080CT11 & 090СТ11 & & \\
\hline 80 & 8 & 5 & 5 & 0 & $140 \mathrm{OT} 11$ & $180 \mathrm{CT} 11$ & & \\
\hline 90 & 9 & 3 & 3 & 0 & $190 \mathrm{CT} 11$ & $210 \mathrm{CT} 11$ & & \\
\hline 100 & 10 & 2 & 2 & 0 & $210 \mathrm{CT} 11$ & $220 \mathrm{CT} 11$ & & \\
\hline 110 & 11 & 1 & 1 & 0 & $230 \mathrm{CT} 11$ & $230 \mathrm{CT} 11^{*}$ & \multirow{5}{*}{\multicolumn{2}{|c|}{$\begin{array}{l}\nabla 11 \\
\Delta \nabla \nabla 12 \\
\Delta \nabla \nabla 13 \\
\Delta \nabla \nabla 14 \\
\Delta \nabla 15\end{array}$}} \\
\hline 120 & \begin{tabular}{|l|}
12 \\
\end{tabular} & 8 & 8 & 0 & $240 \mathrm{CT} 11$ & 310CT11 & & \\
\hline 130 & 13 & 5 & 5 & 0 & $260 \mathrm{CT} 11$ & $300 \mathrm{CT} 11$ & & \\
\hline 140 & 14 & 4 & 4 & 0 & $280 \mathrm{CT} 11$ & $310 \mathrm{CT} 11$ & & \\
\hline 150 & 15 & 8 & 8 & 0 & 05NOV $11^{*}$ & 12NOV11 & & \\
\hline 160 & 16 & 9 & 9 & 0 & 07NOV11 & 15NOV11 & \multirow{5}{*}{\multicolumn{2}{|c|}{ 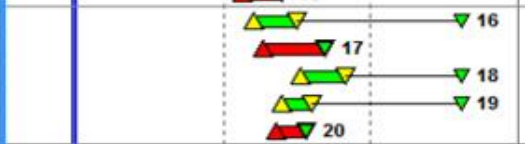 }} \\
\hline 170 & 17 & 13 & 13 & 0 & 09NOV11 & 21 NOV11 & & \\
\hline 180 & 18 & 9 & 9 & 0 & 17NOV11 & 25 NOV 11 & & \\
\hline 190 & 19 & 6 & 6 & 0 & 13NOV11 & 18NOV11 & & \\
\hline 200 & 20 & 6 & 6 & 0 & 12 NOV 11 & 17NOV11 & & \\
\hline 210 & 21 & 14 & 14 & 0 & 14NOV11 & 27NOV11 & \multirow{5}{*}{\multicolumn{2}{|c|}{$\begin{array}{l}\Delta 21 \\
\nabla 22 \\
\Delta \nabla 23 \\
\Delta \nabla 225\end{array}$}} \\
\hline 220 & 22 & 9 & 9 & 0 & 16NOV11 & $24 \mathrm{NOV} 11$ & & \\
\hline 230 & 23 & 11 & 11 & 0 & 16NOV11 & 26NOV11 & & \\
\hline 240 & 24 & 3 & 3 & 0 & 22 NOV11 & $24 \mathrm{NOV} 11$ & & \\
\hline 250 & 25 & 6 & 6 & 0 & 23NOV11 & 28NOV11 & & \\
\hline 260 & 26 & 10 & 10 & 0 & 27 NOV11 & 06DEC11 & & \multirow{4}{*}{$\begin{array}{l}\nabla 26 \\
\Delta \nabla 27 \\
\Delta-\nabla 28 \\
\nabla 29\end{array}$} \\
\hline 270 & 27 & 7 & 7 & 0 & 07DEC11 & 13DEC11 & & \\
\hline 280 & 28 & 8 & 8 & 0 & 11DEC11 & 18DEC11 & & \\
\hline 290 & 29 & 1 & 1 & 0 & 19DEC11 & 19DEC11 & & \\
\hline
\end{tabular}

Figure (9): project schedule at solution $Z 1=80$ days and $Z 2=47171$ units.

It is noticed that activity 15 starts at 5/11/2011 (this means 35 days after project starts) and project finish at 19/12/2011 (80 days after project start).

\subsection{Fixed bonuses cost:}


In addition to the variable bonuses cost in the original case, a fixed bonuses cost (1000 units) for a project completion duration earlier th an 80 days is considered. The resulted TCT curve is presented in Figure (10).

It is noted that a decreasing of total cost has been occurred for all solutions with $\mathrm{Z} 1<80$ days due to the adding of fixed bonuses cost.

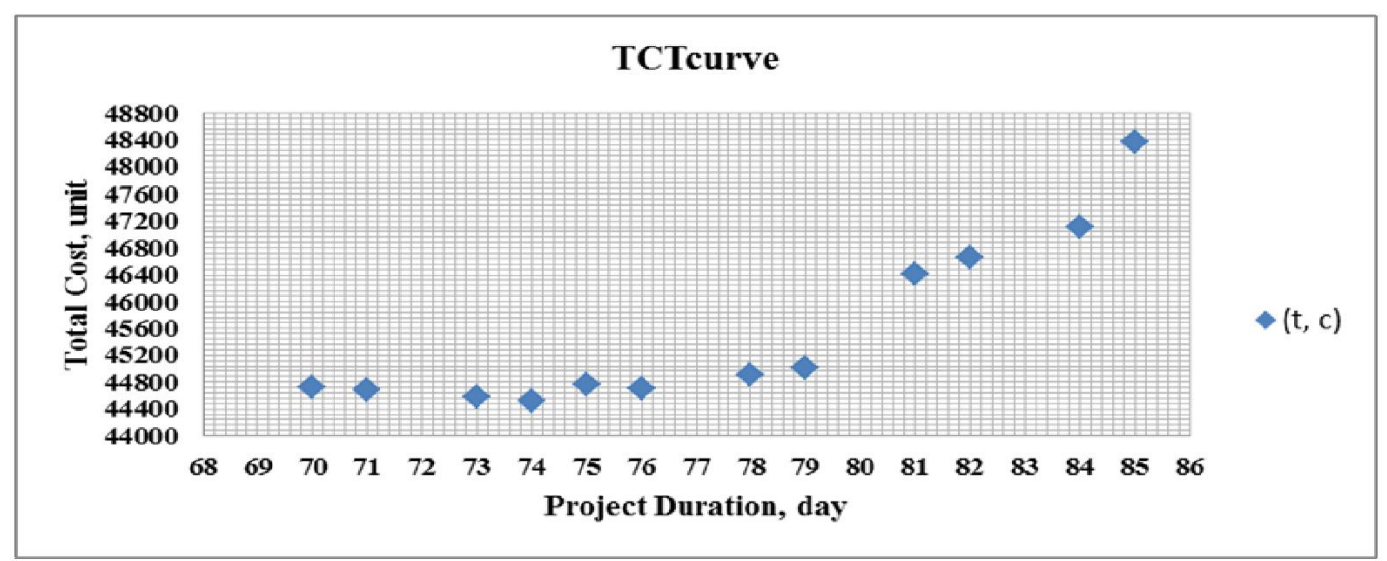

Figure (10): Optimum TCT curve considering 1000 units of fixed bonuses cost

\subsection{Fixed penalty cost:}

In addition to the variable penalty cost in the original case, a fixed penalty cost (1000 units) for project completion durations later than 80 days is considered. The resulted TCT curve is presented in Figure (11).

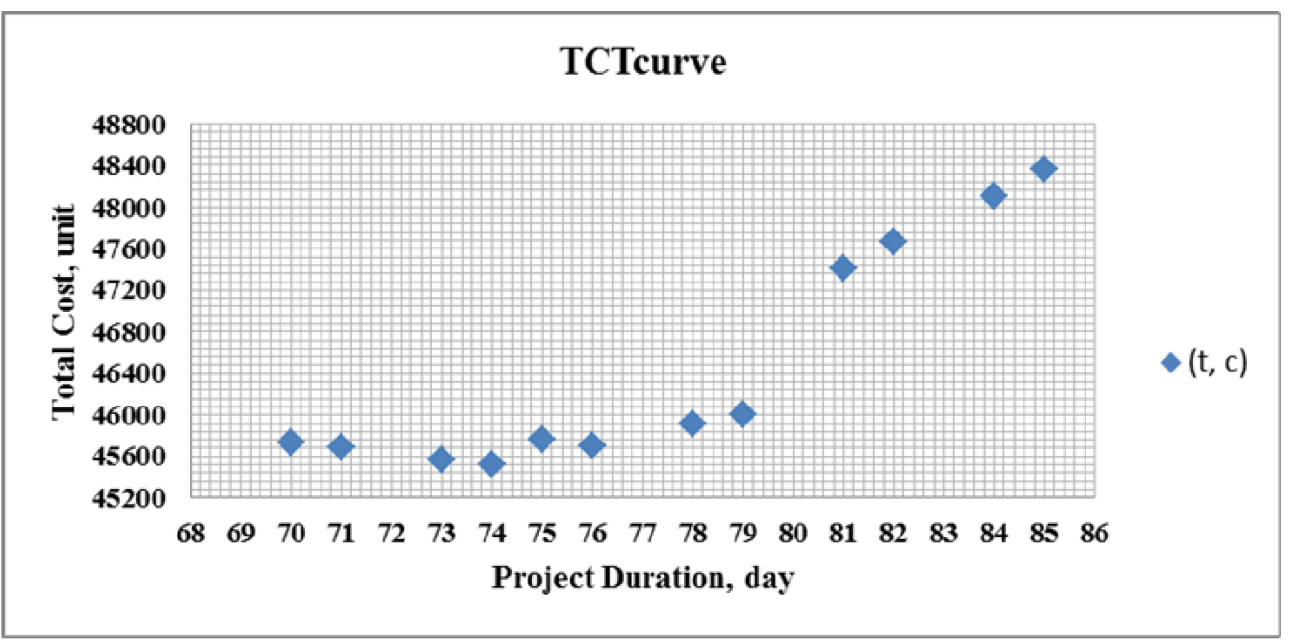

Figure (11): Optimum TCT curve considering 1000 units of fixed penalty cost

It can be seen that an increasing of total cost has been occurred for all solutions with $\mathrm{Z} 1>80$ days due to the added fixed penalty cost.

\subsection{Fixed indirect cost:}


In addition to the variable indirect cost in the original case, a fixed indirect cost equal to 1000 units is considered. The resulted TCT curve is presented in Figure (12). It is observed that an increasing of total cost has been occurred for all solutions.

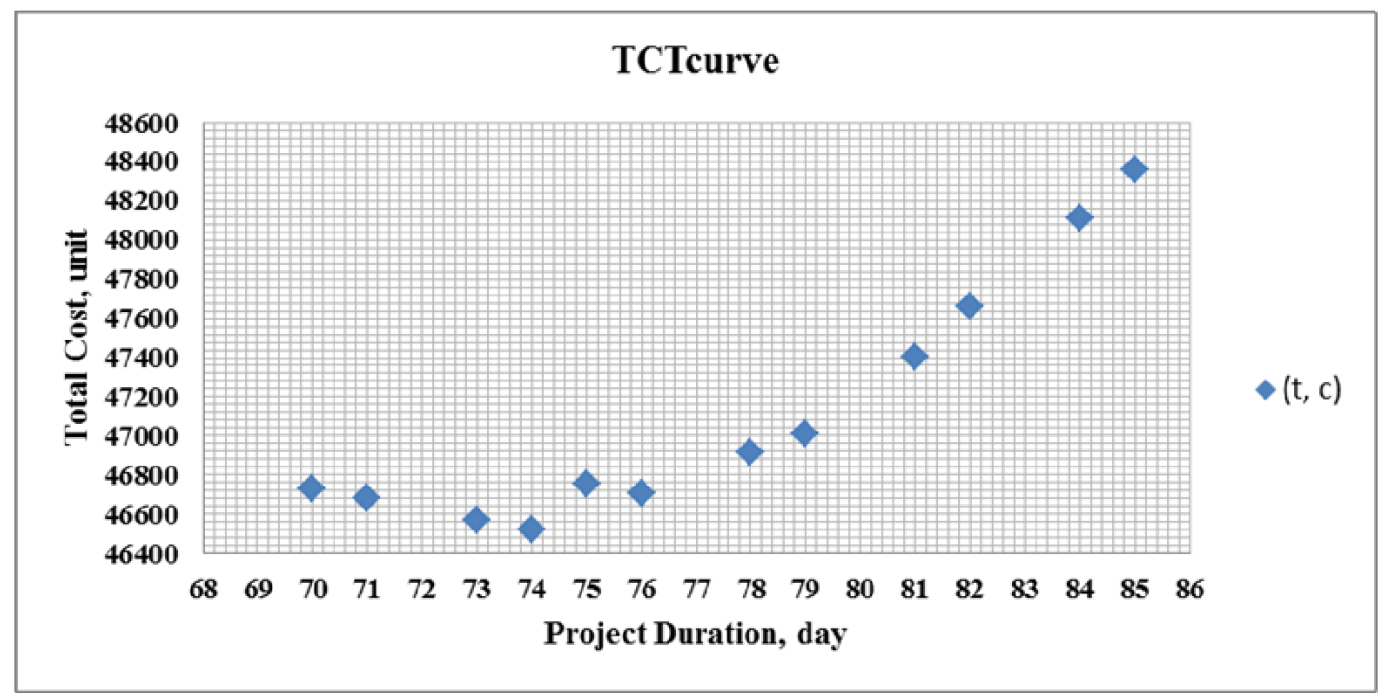

Figure (12): Optimum TCT curve considering fixed indirect cost (1000 units)

\subsection{Real time factor:}

Considering 5 working days per week, the real time factor $(\alpha)=7 / 5=1.4$. TCT curve for this case is drawn as follows:

1- Membership function will take the following new boundaries:

$\lambda 1=\left(85^{*} 1.4-\mathrm{Z1}\right) /(85-70) * 1.4=(119-\mathrm{Z} 1) /(119-98)$.

2- The constraint related to activity 11 (activity 11 finish at 23 days after project start) is given for a case of 7 working days per week. In this case the equivalent finish time of activity 11 equal to $23 * 1.4 \approx 32$ days. The resulted TCT curve is plotted in Figure (13).

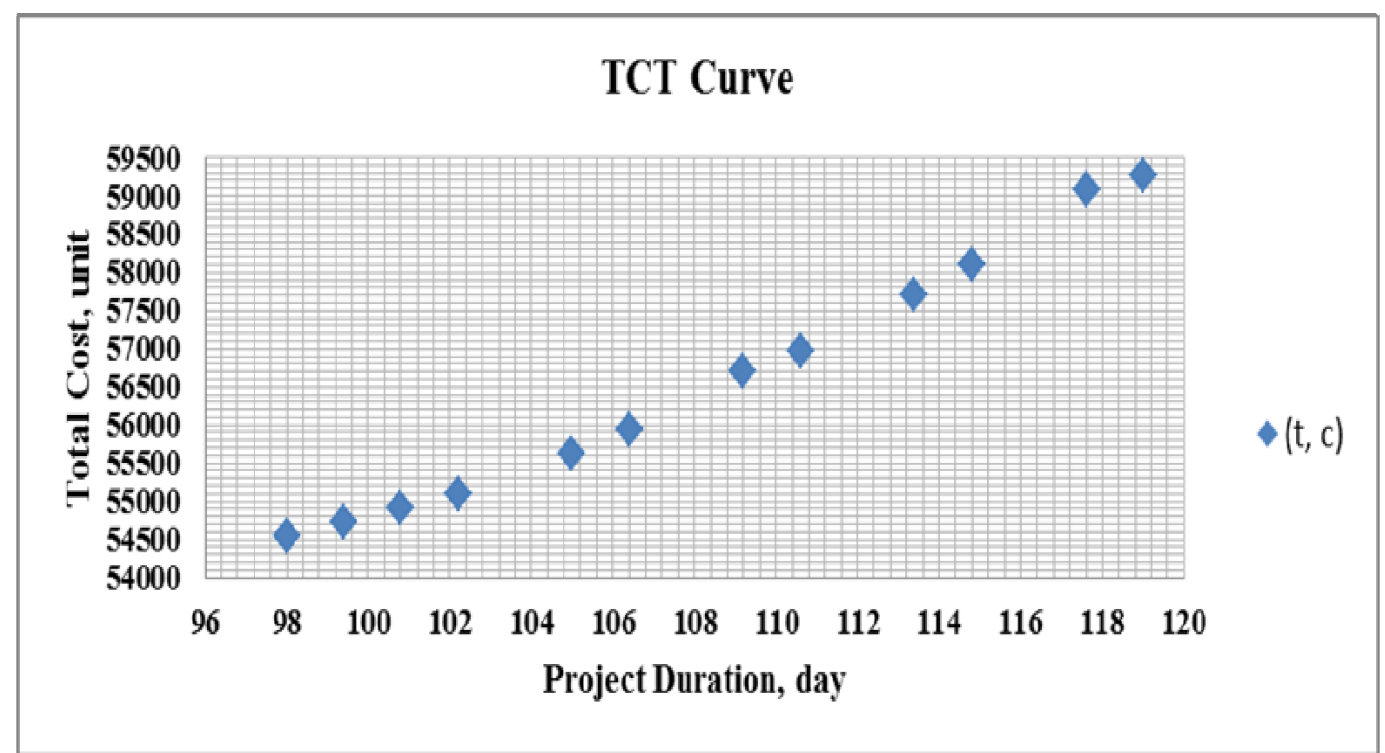

Figure (13): Optimum TCT curve considering 5-working days per week ( $\alpha=7 / 5=$ 1.4) 
It is clear that a valuable increasing in the total cost has been occurred due to the increasing of indirect and penalty costs. The existence of 2 holiday days per week caused an increasing in project duration (Z1). Indirect and penalty costs increased proportionally with respect to the increase of Z1. To verify this case, $\mathrm{P} 3$ is used to schedule project activities at the solution $\mathrm{Z} 1=98$ days and $\mathrm{Z} 2=$ 54531 units. The schedule is shown in Figure (14).

It is noticed that project starts at 1/10/2011 and finishes at 7/1/2012. (99 days), however, the model results duration is 98 days. The one-day difference is related to the reason that, P3 is affected by the chosen of holiday days, project start day, and the resulted finish day, while the model cannot consider these factors.

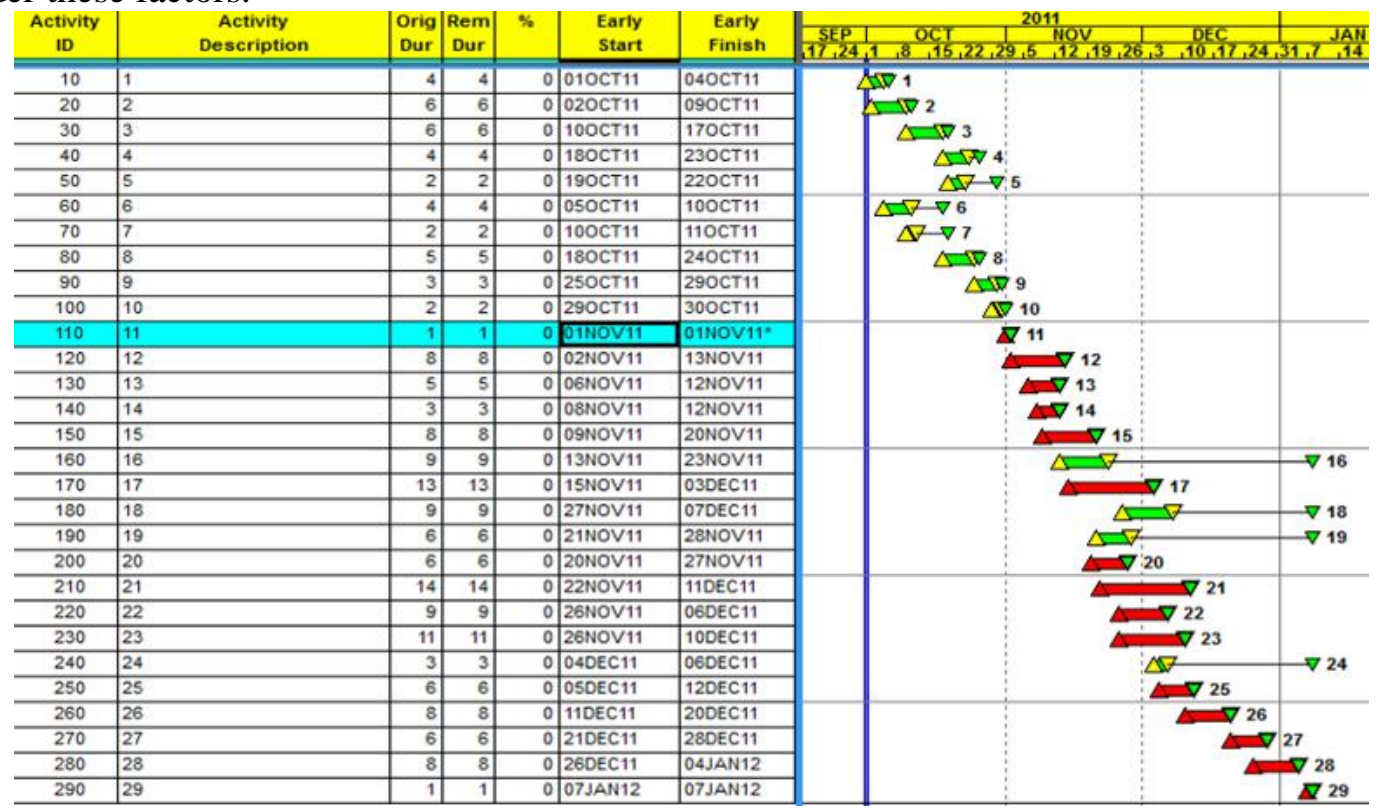

Figure (14): Project schedule for 5-working days per week $(Z 1=98$ days, $Z 2=$ 54531 units)

\section{Conclusion:}

In this work, an Integer Linear model combining most factors and characteristics presented in previous works and related to TCT problems was proposed. Also, other factors such as fixed indirect, fixed penalty, and fixed bonuses costs were introduced in the model. for best real representation of life projects, the weekly holiday days were considered in the model by introducing real time factor $(\alpha)=7 /$ (number of working days per week). A procedure method to get optimum time-cost solutions was presented. The optimum time-cost solutions were plotted in so-called TCT curve to enable decision maker to choose the appropriate solution for the problem.

A sensitivity analysis was conduct ed to test the model reaction against different affected factors. The sensitivity analysis showed good reaction of the model to the different solved cases. The new resulted activities durations (after crashing) for different solutions were scheduled using primavera project planner (P3). The aim of this process was to ensure that model scheduled project activities at minimum durations. The comparison showed that results were fitting well.

\section{$\underline{\text { References }}$}

[1] D. L. Mon, C. H. Cheng, and H. C. Lu, 1995. Application of fuzzy distributions on project management. Fuzzy set and systems, 73, 227-234. 
[2] H. Tareghian and S. H. Taheri, 2007. A solution procedure for the discrete time, cost and quality tradeoff problem using electromagnetic scatter search. Applied Mat hematics and Computation, 190, 1136-1145.

[3] E. Eshtehardian, A. Afshar, and R. abbasnia, 2009. Fuzzy-based MOGA approach to stochastic time-cost tradeoff problem. Automation in Construction, 18, 692-701.

[4] T. Błaszczyk and M. Nowak, 2009. The TCT analysis in construction project using computer simulation and interactive procedure. Baltic Journal on Sustainability, 15(4), 523-539.

[5] O. Hazir, M. Haouaric , and D. ErdalErelb , 2008. Discrete TCT problem: A decompositionbased solution algorithm for the budget version. Computers \& Operations Research, 37, 649 - 655.

[6] K. P. Anagnostopoulos and L. Kotsikas, 2010. Experimental evaluation of simulated annealing algorithms for the TCT problem. Applied Mathematics and Computation, 217, 260-270.

[7] S. P. Chen and M. J. Tsai, 2011. Time-cost-off analysis of project network in fuzzy environment. Europen Journal of operation research, 211, 386-397.

[8] M. Rahimi and H. Iranmanesh , 2008. Multi Objective Particle Swarm Optimization for a Discrete TCQT Problem. World Applied Sciences Journal 4 (2): 270-276, 2008 ISSN 1818-4952.

[9] F. S. Hillier and G. J. Lieberman, 2001. Introduction to operation researches, Seventh Edition. Published by McGraw-Hill, an imprint of The McGraw-Hill Companies, Inc., 1221 Avenue of the Americas, New York, NY, 10020.

[10] A .J. G. Babu and N. Suresh, 1996. Project management with time, cost and quality considerations. Journal of operation research, 88, 320-327.

[11] F. Arikan and Z. Gungor, 2001. An application of fuzzy goal programming to multiobjective project network problem. Fuzzy sets and systems, 119, 49-58.

[12] S. Sakellaropoulos and A. B. Chassiakos, 2004. Project time-cost analysis under generalized precedence relations. ELSEVIER, Advances in Engineering Software, 35, 715-724.

[13] C. Ananya and Chakraborte M., 2010. Cost-time Minimization in a Transportation Problem with Fuzzy Parameters: A Case Study. Jour nal of transportation system engineering and information technology. Volume 10, Issue 6, December 2010. 